Gut, 1974, 15, 845-851

\title{
Excisional surgery with ileostomy for Crohn's colitis with particular reference to factors affecting recurrence
}

\author{
D. M. STEINBERG ${ }^{1}$, R. N. ALLAN, H. THOMPSON, B. N. BROOKE ${ }^{2}$, \\ J. ALEXANDER-WILLIAMS ${ }^{3}$, AND W. T. COOKE
}

From the Nutritional and Intestinal Unit, The General Hospital, Birmingham

SUMMARY This paper reports the indications for, and results of, excision of the large intestine with ileostomy in 73 patients with Crohn's colitis who have been followed for a mean of nine years since resection. Sixty-four of them are still alive and all but two of the survivors are now in good health.

However, $23(33 \%)$ have developed recurrent Crohn's disease since resection. This is higher than that reported in many other series and may be due to differences in the length of follow up, the site and extent of colonic disease, the age of the patient at the time of excision with ileostomy, and differences in the pathological interpretation of the diagnosis of Crohn's disease. The high recurrence rate in this series lends caution to the view that the prognosis after excisional surgery and ileostomy for Crohn's colitis is as good as after the same operation for ulcerative colitis and should influence the decision when the alternative of medical or surgical management are being considered for patients with Crohn's colitis.

The medical management of Crohn's colitis frequently fails to control symptoms (Howel-Jones, Lennard-Jones, and Lockhart-Mummery, 1966) and operative treatment either by defunctioning ileostomy or ileo-rectal anastomosis has not been entirely satisfactory (Burman, Cooke, and Williams, 1971). Proctocolectomy with ileostomy has been claimed to be effective in restoring patients with severe disease to good health (Ritchie and LockhartMummery, 1973) but there is some doubt as to the incidence of recurrence of Crohn's disease after this operation. A $7 \%$ incidence is reported by Ritchie and Lockhart-Mummery (1973) from St Mark's Hospital and $11 \%$ by De Dombal, Burton, and Goligher (1971) from Leeds. Nugent, Veidenheimer, Meissner, and Haggitt (1973) from the Lahey Clinic found only one recurrence $(3.6 \%)$ after general surgery and ileostomy in 28 patients followed for 10 to 15 years. Such reports seem to confirm early concepts that Crohn's disease could remain confined to the large bowel and that therefore low recurrence

\footnotetext{
${ }^{2}$ Supported by a Raine travelling scholarship of the University of Western Australia

'St George's Hospital, London

${ }^{3}$ External scientific staff, Medical Research Council

Received for publication 27 June 1974.
}

rates should follow excision of the colon (Wells, 1952; Brooke, 1959; Lockhart-Mummery and Morson, 1960). In contrast, Korelitz, Present, Alpert, Marshak, and Janowitz (1972) have shown a $46 \%$ recurrence rate when Crohn's colitis was treated by excision with ileostomy.

This paper reports the indication for, and results of, surgery in 73 patients having excisional surgery with ileostomy for Crohn's colitis between 1950 and 1972 and the incidence of recurrent disease, and includes a discussion of the factors which might explain the striking differences between the recurrence rates in this and other reported series.

\section{Materials and Methods}

The clinical, radiological, and pathological criteria for distinguishing ulcerative colitis and Crohn's colitis are identical to those of Lockhart-Mummery and Morson'(1960 and 1964) and of Lindner, Marshak, Wolf, and Janowitz (1963). The criteria for the diagnosis of recurrence have been based on histology after surgical resection in all but three patients who have characteristic radiological changes.

The results of excisional surgery with ileostomy for Crohn's colitis have been analysed in a consecutive series of 418 patients with Crohn's disease treated at the General Hospital, Birmingham, 
between 1942 and 1973. The disease affected the small bowel alone in $2 \mathrm{q} 4$, the large and small bowel in 136, and the large bowel alone in 68. Of the 204 patients with large bowel involvement, 73 (40 men and 33 women) were treated by excisional surgery with ileostomy.

The mean age at onset of symptoms in men was 27.2 years (range 13-67 years) and 21.6 years (range 11-40 years) in women. Forty-two patients ran a course of continuous symptoms with diarrhoea, abdominal pain, general malaise, and weight loss while 29 ran a chronic intermittent course. Two of them presented with acute fulminating disease. There was a mean interval of 6.1 years between the onset of symptoms and excisional surgery with ileostomy. Twenty-seven patients had had a previous bowel resection (table I).

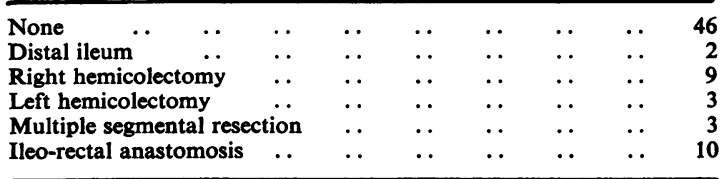

Table I Previous surgery in patients undergoing excisional surgery with ileostomy

Operation was usually undertaken when medical treatment or previous surgery had failed to control symptoms. Thirty-eight patients were submitted to surgery because their symptoms persisted despite corticosteroid therapy. Contributory factors included the presence of perianal disease in 30 patients (in seven florid perianal disease was the main indication for excision), six had obstructive features, two fistulae, and one acute dilatation of the colon.

The extent of colonic involvement is shown in table II. In 38 of the 73 patient the distal small bowel was involved. Thirty-six patients were treated by a one-stage panproctocolectomy, while five had a twostage procedure. Early in the series 12 patients were treated by a temporary ileostomy followed later by a panproctocolectomy. Seven patients had colectomy with ileostomy where the proximal rectum was exteriorized as a mucous fistula and three had a colectomy, ileo-rectal anastomosis, and a defunctioning ileostomy. Ten patients treated previously by ileo-rectal anastomosis were submitted to excision

\begin{tabular}{|c|c|c|c|c|c|c|c|c|}
\hline \multirow{2}{*}{\multicolumn{3}{|c|}{ Total colon and rectum ... }} & 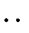 & $\cdots$ & $\cdots$ & $\cdots$ & . & 5 \\
\hline & & & . & . & . & . & . & \\
\hline Left side only & . & $\cdots$ & $\cdots$ & $\ldots$ & $\ldots$ & $\ldots$ & .. & \\
\hline Right side only & .. & . & . & . & . & . & .. & \\
\hline Not known & .. & . & . & . & . & . & . & \\
\hline
\end{tabular}

Table II Extent of colonic involvement of the rectum with ileostomy because of persistent diarrhoea, general malaise, and perianal sepsis.

\section{Results}

\section{MORBIDITY AND MORTALITY}

\section{Operative mortality}

Three of the 73 patients died, an operative mortality rate of $4.1 \%$. Two developed peritonitis complicated by septicaemia and bronchopneumonia and one died from a massive haemorrhage due to a disorder of coagulation.

\section{Early morbidity}

Twenty-four experienced ileostomy dysfunction (either mechanical obstruction or profuse ileostomy output) in the first four weeks after excisional surgery and six were treated surgically for the relief of mechanical obstruction either at or immediately proximal to the stoma. The commonest site of sepsis was the perianal wound after proctectomy which occurred in 21 out of 64 patients. Six had major peritoneal sepsis and eight major abdominal wound infections.

\section{Late mortality}

The late mortality related to the disease was $7 \cdot 1 \%$ ( 5 out of 70 ), four of whom died after resection of recurrent disease (see below) and the other after insertion of a $\mathrm{T}$ tube for stenosing cholangitis. There was one additional but unrelated death due to cerebrovascular disease.

\section{Late morbidity}

All the survivors have been reviewed regularly with recent clinical, radiological, biochemical, and haematological assessment. The mean duration of follow up since ileostomy was 8.7 years. During this time $45(64 \%)$ of the 70 patients followed have been re-admitted on 96 occasions (table III).

\section{RECURRENT DISEASE}

\section{Recurrence rate}

Twenty-three have had evidence of recurrent disease,

\begin{tabular}{|c|c|c|c|c|c|c|c|c|}
\hline \multirow{2}{*}{\multicolumn{5}{|c|}{$\begin{array}{l}\text { Recurrence (treated surgically) . . } \\
\text { Ileostomy reconstruction (no recurrence) }\end{array}$}} & . & . & . & 29 \\
\hline & & & & & $\cdot$ & .. & . & \\
\hline \multirow{2}{*}{\multicolumn{3}{|c|}{$\begin{array}{l}\text { Ileostomy flux } \\
\text { Obstruction due to adhesions }\end{array}$}} & . & .. & . & .. & . & \\
\hline & & & . & .. & . & .. & . & \\
\hline \multirow{4}{*}{$\begin{array}{l}\text { Perianal sepsis } \\
\text { Weakness and an } \\
\text { Jaundice } \\
\text { Other operations }\end{array}$} & . & . & . & . & . & .. & . & \\
\hline & lemia & . & . & . & . & .. & . & \\
\hline & .. & . & . & .. & . & .. & . & \\
\hline & .. & .. & . & . & . & . & . & \\
\hline Total & .. & .. & . & . & . & . & . & \\
\hline
\end{tabular}

Table III Causes of readmission after excisional surgery with ileostomy in 45 patients with Crohn's disease 
a recurrence rate of $33 \%$. Twenty ( $29 \%$ ) have had further resections for histologically proven recurrent disease on 25 occasions. Three others, and one patient who has already had a resection for recurrent disease have radiological evidence of recurrence.

Table IV shows the principal clinical features. Subacute obstruction, occurring at or just proximal to the stoma, was the major feature in nearly half the patients. Obstruction was associated with intermittent profuse ileostomy output in eight patients, with overt bleeding in three, and in two was complicated by a perforation of the terminal ileum. Five of this group presenting with obstructive features had recurrence at the stoma with ulcers, stenosis, or cutaneous fistulae. Abscess and fistula was the mode of presentation on seven occasions: four through paramedian scars, one at a right subcostal drain site, and two adjacent to the ileostomy. Three of these episodes were due to jejunal recurrence in two patients.

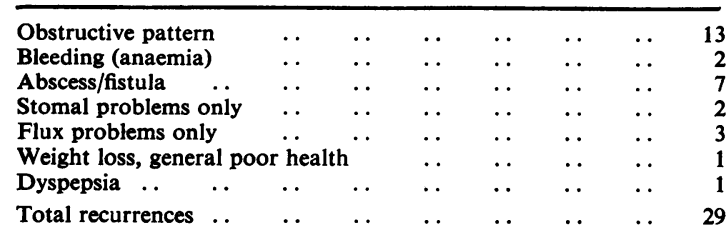

Table IV Presentation of recurrent proximal disease

\section{$X$-ray diagnosis}

In 23 of the 29 episodes of recurrence a barium follow-through combined with a limited ileostomy enema showed radiological abnormality, usually a narrow segment of the terminal ileum with proximal dilatation. Demonstrations of external fistulae were successful using a combined sinogram followthrough technique to demonstrate the connexion and also the extent of any underlying disease. Recurrent disease was found at laparotomy on six occasions despite negative radiology, emphasizing the difficulty of radiological demonstration of the ileum immediately proximal to the stoma.

\section{Laboratory investigations}

Haematological and/or biochemical abnormalities at the time of recurrence were present in 17 patients: three were only anaemic (haemoglobin <12 g\%) while $14(60 \%)$ had biochemical evidence of active disease (albumin $<4 \mathrm{~g} \%$ and seromucoids $>150$ $\mathrm{mg} \%$ ).

\section{Site of recurrence}

The site of recurrence is shown in table V. Disease

\begin{tabular}{|c|c|c|c|c|c|c|c|c|}
\hline \multirow{2}{*}{\multicolumn{2}{|c|}{ Terminal ileum $\ldots$}} & $\cdots$ & $\cdots$ & $\cdots$ & $\cdots$ & $\cdots$ & $\cdots$ & 20 \\
\hline & & $\ldots$ & . & . & . & . & . & 5 \\
\hline Jejunal $\quad$. & . & .. & . & . & . & . & . & 3 \\
\hline Gastric (antral) & . & $\cdots$ & $\cdots$ & $\cdots$ & . & . & $\cdots$ & 1 \\
\hline
\end{tabular}

Table V Site of recurrent disease (29 recurrences)

involving the terminal ileum is defined as that occurring within $25 \mathrm{~cm}$ of the stoma. Of the five with extensive small bowel disease one had jejunal and ileal disease and the others diffuse involvement confined to the ileum. One patient had a gastric recurrence initially misdiagnosed as a prepyloric ulcer.

\section{Histopathology}

Pathological examination was performed on the resected specimens in 20 patients. In all but two the histological material has been reviewed by one of the authors (H.T.). Epithelioid follicles with Langhan's giant cells were identified in 14. Of the remaining six there were transmural inflammation and fissuring in four and in the other two from whom tissue was no longer available for study the pathological reports written at the time favoured a diagnosis of recurrent Crohn's disease.

\section{TREATMENT OF RECURRENCE}

Twenty of the 23 patients with recurrence have undergone 26 resections. Excision of the terminal ileum with refashioning of the ileostomy was performed on 20 occasions and a proximal resection on four occasions (three times in the same person all for jejunal disease. A gastric recurrence was treated initially with vagotomy and pyloroplasty but symptoms persisted until an antrectomy produced a satisfactory result.

Four patients (including one who has already had a resection for recurrent disease) have extensive small bowel involvement demonstrated radiologically. Three are receiving ACTH, and the other, with recurrent bleeding, haematinics only. All four are now symptomatically controlled and two of them have shown radiological and biochemical improvement.

\section{Mortality from recurrent disease}

Four patients died after operations for recurrent disease: three following resections of the ileum (two with fistulae complicating perforation and one with extensive disease) and another after a diagnostic laparotomy at which irresectable diffuse small intestinal involvement was found. Deaths were due to septicaemia, electrolyte imbalance, or pulmonary emboli. 


\section{FACTORS AFFECTING RECURRENCE RATE}

\section{Length of follow up}

In our series the majority of recurrences have occurred within five years (14 of 23), the remainder occurring at varying intervals up to 19 years after ileostomy (fig 1). A cumulative recurrence graph demonstrating the wide scatter in the length of follow up is shown in figure 2 . The recurrence risk is considered as the percentage of the number of recurrences against the total number of patients followed in each particular year. There was a $10 \%$ incidence in the first year and thereafter an annual $5 \%$ risk a cumulative incidence to $100 \%$ at 18 years. All six patients followed for more than 15 years after ileostomy have suffered at least one recurrence.

Site and extent of disease

Fifty-three per cent had histologically confirmed

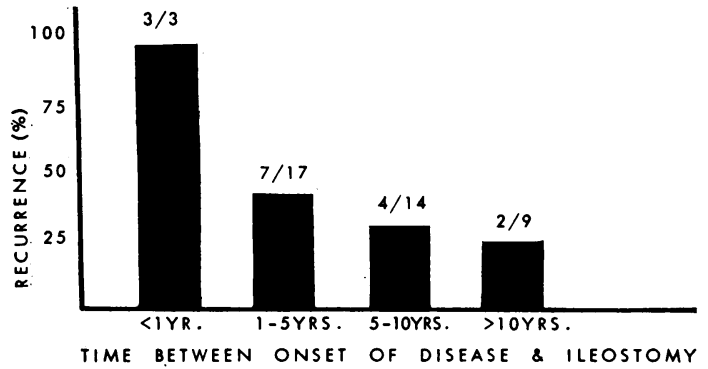

Fig 1 Time interval for recurrence after ileostomy and colectomy.

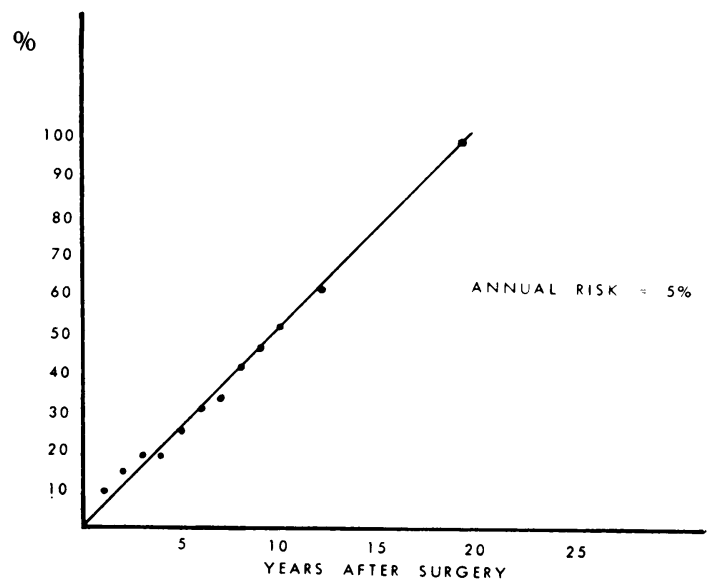

Fig 2 Cumulative recurrence graph after ileostomy and colectomy. ileal involvement at the time of excisional surgery. There was no significant difference in the risk of development of recurrence whether or not the ileum was involved. Thirteen recurrences occurred in 37 patients with initial ileal involvement compared with 10 recurrences in 33 patients whose ileum was considered normal.

The patients have been divided into three groups: those whose large bowel was wholly involved, those with disease confined to the left side, and those with right-sided disease.

If only colonic involvement is considered whether the small intestine is involved or not (table VI) then in those with left-sided disease all six recurred more than five years after surgery (fig 3), whilst 15 of 17 recurrences with total colonic involvement occurred within five years of ileostomy.

\begin{tabular}{llll}
\hline & $\begin{array}{l}\text { Total } \\
\text { Involvement }\end{array}$ & $\begin{array}{l}\text { Right- } \\
\text { sided }\end{array}$ & $\begin{array}{l}\text { Left- } \\
\text { sided }\end{array}$ \\
\hline $\begin{array}{l}\text { Birmingham series } \\
\text { (75 patients) }\end{array}$ & $83 \%$ & $2 \%$ & $15 \%$ \\
$\begin{array}{c}\text { St Mark s series } \\
\text { (90 patients) }\end{array}$ & $53 \%$ & $3 \%$ & $44 \%$ \\
\hline
\end{tabular}

Table VI Distribution of colonic Crohn's disease in patients receiving non-restorative surgery for Crohn's disease $^{1}$

IIleostomy and colostomy

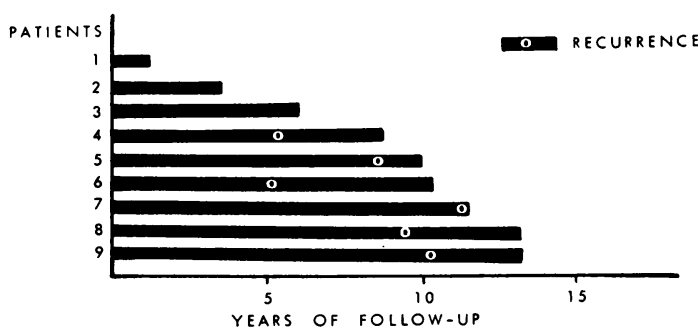

Fig 3 The development of recurrence in patients treated by ileostomy and colectomy for Crohn's disease confined to left side of colon.

Age at excisional surgery

The mean age at the time of excisional surgery with ileostomy was 33.3 years. The incidence of recurrence compared with age at excisional surgery with ileostomy is shown in a cumulative recurrence graph for patients above and below the age of 40 at the time of excisional surgery and ileostomy (fig 4). The younger group had both an initially higher incidence of recurrence and a higher annual incidence subsequently. 


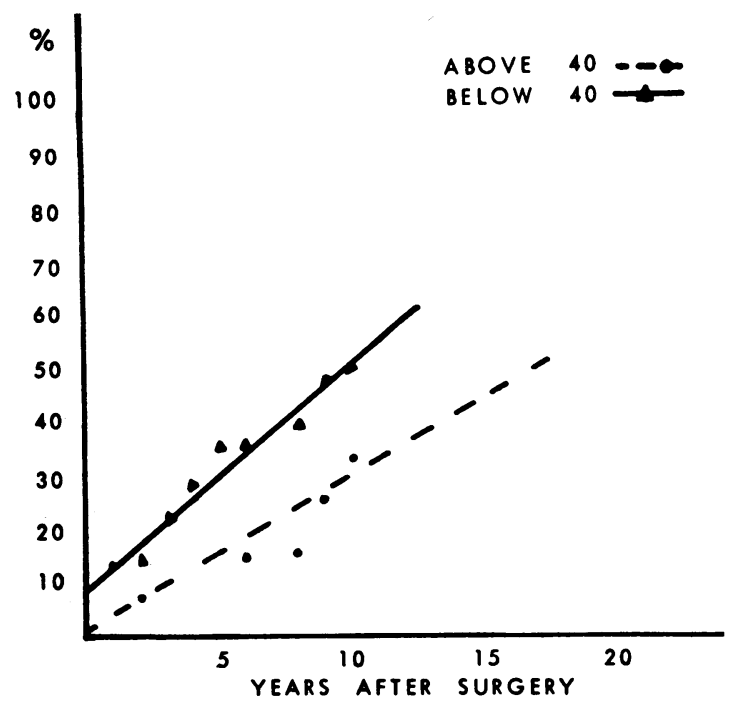

Fig 4 A comparison of cumulative recurrence risk above and below the age of 40 .

Duration of disease before excisional surgery and ileostomy

According to the interval between the onset of symptoms and the time of excisional surgery and ileostomy, the patients have been divided into four groups. The incidence of recurrence in each group five years after surgery is shown in figure 5 . The numbers in each group are too small for statistical comparison but suggest a trend towards a higher recurrence risk with a shorter length of history before excisional surgery.

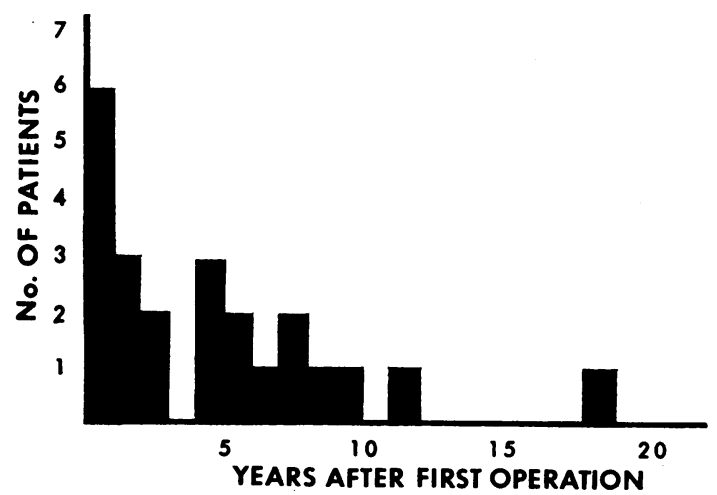

Fig 5 The incidence of recurrence at five years compared with varying duration of disease before ileostomy and colectomy.
Era and surgeon

Until 1963 the operations were performed by one author (B.N.B.) and since then by another (J.A.W.). This allows a convenient division of the series into two eras. The crude overall recurrence rate appears to indicate a higher recurrence rate in the first era (table VII). However, a comparison of the recurrence rate in those patients followed for five years after resection shows that there was no significant difference between the two and that it is easy to be misled by considering crude recurrence rates in isolation from the length of follow up.

\begin{tabular}{|c|c|c|}
\hline Recurrence & $\begin{array}{l}\text { Surgeon Era } \\
\text { B.N.B. 1947-1963 }\end{array}$ & $\begin{array}{l}\text { Surgeon Era } \\
\text { J.A.W. 1963-1973 }\end{array}$ \\
\hline $\begin{array}{l}\text { Overall } \\
\text { Number of patients } \\
\text { Total recurrence to date }\end{array}$ & $\begin{array}{l}32 \\
14 \text { (44\%) }\end{array}$ & $\begin{array}{r}38 \\
9\end{array}$ \\
\hline $\begin{array}{l}\text { At five years } \\
\text { Number of patients } \\
\text { Recurrence at } 5 \text { years }\end{array}$ & $\begin{array}{r}32 \\
7\end{array}$ & $\begin{array}{r}20 \\
6 \quad(30 \%)\end{array}$ \\
\hline
\end{tabular}

Table VII Recurrence rates in the two surgical eras

\section{One-stage or multiple operations}

The risk of recurrence was the same if the operation was done as a one-stage panproctocolectomy or a multiple-staged procedure. Ten of the 35 patients treated by a one-stage panproctocolectomy developed recurrence of disease compared with 13 of the 35 undergoing multiple staged procedures. There was an equal distribution of single and multistaged operations in this centre between 1950 and 1972. Furthermore, there was no significant difference in the risk of proximal recurrence if the rectum was left in situ at the time of colectomy (two recurrences in nine patients).

CURRENT STATUS OF ALL PATIENTS

Sixty-four of the original 73 patients are still alive, including 19 of the 23 who have had recurrent disease.

All but one of these 19 are currently in good health; however, three of them have previously experienced such prolonged illness and hospital treatment that their overall course since ileostomy can hardly have been considered satisfactory, while eight (four with radiological recurrence) suffer minor disability from episodes of profuse ileostomy output and anaemia but are nevertheless considered to be in good health because their symptoms are well controlled and they are at work.

The other 45 are all well except one patient with an obsessional neurosis which antedates the onset of the Crohn's disease. 
Of the 64 survivors, 36 are taking supplements of potassium, iron, and folic acid, and eight are still receiving steroid therapy. Fifty patients $(78 \%)$ were within normal limits as regards haematological and biochemical status (haemoglobin $>12.0 \mathrm{~g} \%$; albu$\min >4 \mathrm{~g} \%$; seromucoids < $150 \mathrm{mg} \%) ; 14(22 \%)$ showed abnormality in one or more respects.

\section{Discussion}

One third of our patients with Crohn's disease of the large bowel were treated by excisional surgery with ileostomy. The operative mortality rate of $4.1 \%$ is similar to that reported from other centres. De Dombal et al (1971) reported an operative mortality rate of $5.1 \%$ (two deaths out of 39 ) and Ritchie and Lockhart-Mummery (1973) $3.1 \%$ (two deaths out of 64) for patients treated by panproctocolectomy with ileostomy. Although there is a fairly low operative mortality rate there is a much higher early morbidity rate due to ileostomy dysfunction when compared with panproctocolectomy for ulcerative colitis and a higher late morbidity due to recurrence and further surgery (Steinberg, Allan, Brooke, Cooke, and Alexander-Williams, 1974).

Recurrent disease after excisional surgery with ileostomy has only previously been reported in the terminal ileum (Goligher, 1972; Ritchie and Lockhart-Mummery, 1973) whereas only $70 \%$ of our recurrences have occurred at this site. Our experience in finding evidence of recurrence in the upper intestine is unusual, five developing extensive small bowel disease, three jejunal lesions, and one a gastric lesion.

Careful consideration has been given to the diagnosis of non-specific prestomal ileitis (Turnbull, Weakley, and Farmer, 1964; Knill-Jones, Morson, and Williams, 1970) but none of our patients appeared to fulfil their criteria. Furthermore, many of those followed by Turnbull have subsequently shown a high incidence of recurrent Crohn's disease (Goligher, 1967). In our view recurrent ileitis after excisional surgery is due to recurrent Crohn's disease irrespective of whether or not the ileum was initially involved.

In contrast to the experience of Nugent and colleagues (1973) and Glotzer, Gardner, Goldman, Hinnichs, Rosen, and Zetzel (1970), 11 (48\%) of our 23 patients with recurrent disease presented a major management problem. Four died after an operation for recurrent disease; five had diffuse small bowel recurrence with systemic upset, and two with jejunal recurrence were complicated by abscess and fistulae. However, despite multiple operations in some of them, the overall present health of the survivors is not as bad as that described by Korelitz et al (1972) who reported that only $45 \%$ were well and that 191 were crippled by complications.

Our findings are in accordance with those of Kiefer, Marshall, and Brolsma (1951) and Fielding, Cooke, and Williams (1972) that the incidence of recurrence is related to the length of follow up. This may explain the difference from the study of De Dombal et al (1971) where the follow up period after panproctocolectomy for Crohn's colitis was short. Furthermore, Goligher (1972) only one year later reported further patients in this series who had developed recurrent Crohn's disease.

The different recurrence rates in this and the reported series of Ritchie and Lockhart-Mummery (1973) are not so simply explained. However, the distribution of colonic disease was different as a large number of patients with predominantly leftsided colonic disease were seen at St Mark's Hospital compared with our series (table VI). Ritchie and Lockhart-Mummery (1973) state that the patients with distal colonic disease have a better overall prognosis following excision and ileostomy or colostomy. Our experience of a smaller group with left-sided colonic disease suggests that in general those patients with disease limited to the left colon have an equal risk of developing recurrence to those with diffuse colonic disease.

We found a much higher incidence of ileal involvement at the initial operation ( $53 \%$ ) compared with the $r$ series $(30 \%)$. However, we did not find any significant difference in the recurrence rate whether or not the ileum was involved at the time of excisional surgery, nor can we support the contention of McGovern and Goulston (1968) that granulomatous colitis with involvement of the terminal ileum behaves in a more benign manner than if the disease is confined to the colon. De Dombal et al (1971) suggest that the younger the patient at the time of the first operation the greater the risk of recurrence and our results support this suggestion. This may explain the difference between the $33 \%$ recurrence rate in this series and the $7 \%$ reported by Ritchie and Lockhart-Mummery (1973) with mean ages at operation of 31.5 years and 39 years respectively. Our findings do not support their view that recurrence was more likely to occur after a staged operation than after a panproctocolectomy. The apparent difference between the two series can best be explained by considering the length of follow up. Most of the staged procedures reported by Ritchie and Lockhart-Mummery (1973) were performed during the early years of their experience and have therefore been followed for a longer period with a greater risk of developing recurrence than those patients undergoing a one-stage panproctocolectomy.

Excisional surgery with ileostomy has proved an 
effective method of treating extensive Crohn's disease of the large bowel where medical management has been unsuccessful in controlling symptoms. The operation should not be undertaken lightly, for patients even with total colonic involvement may remain well for many years with conservative treatment alone (Allan, Steinberg, Williams, and Cooke, 1974).

Unlike those patients with ulcerative colitis, excisional surgery with ileostomy for Crohn's disease cannot guarantee a cure but most patients remain in good health apart from a small group who experience transient episodes of ileostomy dysfunction. Nearly all those patients who have developed recurrent disease and undergone further resections have been restored to good health.

References

Allan, R. N., Steinberg, D. M., Williams, J. A., and Cooke, W. T. The medical management of Crohn's colitis. (In preparation).

Brooke, B. N. (1959). Granulomatous diseases of the Intestine. Lancet $2,745$.

Burman, J. H., Cooke, W. T., and Williams, J. A. (1971). Fate of ileorectal anastomosis in Crohn's disease. Gut, 12, 432-436.

De Dombal, F. T., Burton, I., and Goligher, J. C. (1971). Recurrence of Crohn's disease after primary excisional surgery. Gut, 12, 519-527.

Fielding, J. F., Cooke, W. T., and Williams, J. A. (1972). The incidence of recurrence in Crohn's disease. Surg. Gynec. Obstet., 134, 467-469.

Glotzer, D. J., Gardner, R. C., Goldman, H., Hinrichs, H. R., Rosen, H., and Zetzel, L. (1970). Comparative features and course of ulcerative and granulomatous colitis. New Engl. J. Med., 282, 582-587.
Goligher, J. C. (1967). Surgery of Anus, Rectum and Colon, 2nd ed., p. 938. Bailliere, Tindall, and Cassell, London.

Goligher, J. C. (1972). Ileal recurrence after ileostomy and excision of the large bowel for Crohn's disease. Brit. J. Surg., 59, 253-269.

Howel-Jones, J., Lennard-Jones, J. E., and Lockhart-Mummery, H. E. (1966). Experience in the treatment of Crohn's disease of the large intestine. Gut, 7, 448-452.

Kiefer, E. D., Marshall, S. F., and Brolsma, M. P. (1950). The management of chronic regional ileitis. Gastroenterology, 14, 118-130.

Knill-Jones, R. P., Morson, B., and Williams, R. (1970). Prestomal ileitis: clinical and pathological findings in five cases. Quart. $J$. Med., 39, 154, 287-297.

Korelitz, B. I., Present, D. H., Alpert, L. I., Marshak, R. H., and Janowitz, H. D. (1972). Recurrent regional ileitis after ileostomy and colectomy for granulomatous colitis. New Engl. J. Med., 287, 110-115.

Lindner, A. E., Marshak, R. H., Wolf, B. S., and Janowitz, H. D. (1963). Granulomatous colitis: a clinical study. New Engl. J. Med., 269, 379-385.

Lockhart-Mummery, H. E., and Morson, B. C. (1960). Crohn's disease (regional enteritis) of the large intestine and its distinction from ulcerative colitis. Gut, 1, 87-105.

Lockhart-Mummery, H. E., and Morson, B. C. (1964). Crohn's disease of the large intestine. Gut, 5, 493-509.

McGovern, V. J., and Goulston, S. J. M. (1968). Crohn's disease of the colon. Gut, 9, 164-176.

Nugent, F. W., Veidenheimer, M. C., Meissner, W. A., and Haggitt, R. C. (1973). Prognosis after colonic resection for Crohn's disease of the colon. Gastroenterology, 65, 398-402.

Ritchie, J. K., and Lockhart-Mummery, H. E. (1973). Non-restorative surgery in the treatment of Crohn's disease of the large bowel. Gut, 14, 263-269.

Steinberg, D. M., Allan, R. N., Brooke, B. N., Cooke, W. T., and Alexander-Williams, J. (1974). The sequelae of colostomy and ileostomy: comparison between Crohn's colitis and ulcerative colitis. Gastroenterology, in press.

Turnbull, R. B., Jr., Weakley, F. L., and Farmer, R. G. (1964). Ileitis after colectomy and ileostomy for non-specific ulcerative colitis. Dis. Colon Rect., 7, 427-438.

Wells, C. (1952). Ulcerative colitis and Crohn's disease. Ann. roy. Coll. Surg. Engl., 11, 105-120. 